Undas, Vol 14, No 1, Juni 2018: 93-103

\title{
PENGGUNAAN BAHASA ASING DAN DAERAH PADA PAPAN NAMAUSAHA DAN IKLAN (Studi Kasus di Banjarbaru dan Martapura)
}

\author{
The Using of Foreign and Local languages on the Bussiness Banners and \\ Advertisements (Case Study in Banjarbaru and Martapura City)
}

\author{
Nurhidayati Kurniasih \\ Balai Bahasa Kalimantan Selatan \\ Jalan Jenderal Ahmad Yani Km 32,2, Loktabat, Banjarbaru,Kalimantan Selatan, \\ 70712, Telepon (0511) 4772641, Pos-el: HP: 085230851612
}

\begin{abstract}
Abstrak: Penelitian ini bertujuan (1) mendeskripsikan pilihan penggunaan bahasa asing dan bahasa daerah pada papan nama usaha dan iklan di Banjarbaru-Martapura; dan (2) menjelaskan alasan-alasan atau sebab terjadinya pilihan penggunaan bahasa tersebut. Data diperoleh dari sampel purposif berupa papan nama usaha dagang yang diambil di daerah Banjarbaru dan Martapura. Analisis data dilakukan dengan pendekatan deskriptif, yakni mendeskripsikan kesalahan yang ada dari sampel yang diambil. Kerangka teori yang digunakan adalah teori kaidah Pengindonesiaan Kata dan Istilah asing dan teori AIDA (Attention, Interest, Desire,Action). Hasil yang ditemukan dalam penelitian ini adalah (1) banyak ditemukan bahasa penggunaan bahasa Inggris, dan bahasa Banjar dalam satu papan iklan; (2) tiga sebab mengapa terjadi penggunaan bahasa asing dan daerah: a) ikon kekinian digunakan untuk menarik perhatian (attention) konsumen terhadap barang atau jasa meskipun ikon tersebut tidak sejalan dengan bahasa Indonesia, b) penggunaan bahasa yang beda dengan menggunakan tatabahasa dan pilihan kata yang tak lazim (asing) menjadi pilihan agar konsumen tertarik pada usaha/ produk yang diiklankan, dan c) penggunaan bahasa daerah dipilih untuk lebih mendekatkan konsumen dengan detail atau pilihan layanan. Dalam penelitian ini ditemukan bahwa frasa atau istilah daerah digunakan untuk lebih masuk kedalam perasaan konsumen. Dan sebaliknya bahasa Inggris digunakan untuk memberikan kesan terdidik pada pengiklan.
\end{abstract}

Kata kunci: bahasa, iklan, papan usaha dagang, penggunaan bahasa

Abstract: The objective of this study is (1) to describe the choice of using foreign and local languages on the bussiness banners and advertisements in Banjarbaru and Martapura; and (2) to explain the reasons or the cause of using those languages. Data is obtained from purposive samples of business sign board found in Banjarbaru and Martapura city. Data analysis is using descriptive approach; it was describing the error from the sample. This research uses the rule of Indonesianization of foreign words and terms and AIDA theory (Attention, Interest, Desire, Action). The results of this research are (1) many Banjar and foreign languages are used in one business sign board; (2) three reasons of using foreign and local language: 1. latest icon are used to attract consumer's attention to goods and services even though the icon is not relevant to Indonesian Language. 2. Using different languages deviate from grammar and uncommon word choice to attract consumer's attention to the advertisement of product or business. 3. The use of local language is familiar to consumers of detail and services. This research shows that local phrases or terms are used to evoke consumer's feeling. On the other hand, the use of English gives an educated impression to advertisers.

Keywords: language, advertisement, business sign board, language use 



\section{PENDAHULUAN}

Bahasa Indonesia merupakan bahasa yang aktif. Hal ini sangat memungkinkan bahasa Indonesia untuk berubah sesuai dengan dinamika penggunanya. Perubahan yang terjadi bisa menjadi hal yang positif ataupun negatif bergantung perubahan yang terjadi dan kekonsistenan penggunaanya. Positif apabila perubahan yang ada menjadikan bahasa Indonesia lebih mudah untuk dipahami karena menyesuaikan dengan situasi dan kondisi atau lazim disebut konteks kalimat. Namun, bisa jadi menjadi hal yang negatif apabila peubahan tersebut menjadikan bahasa Indonesia menjadi tidak konsisten dengan kosakata yang dimilikinya.

Bahasa merupakan alat pengungkap yang baik dan dapat menimbulkan efek tertentu, bukan saja menggambarkan objek itu semirip mungkin, tetapi dapat juga menunjukkan setepat-tepatnya apa yang dimaksudkan. Selain memiliki kecerma-tan dan pemahaman, seseorang harus memiliki pula kemampuan untuk mempergunakan kata-kata yang tepat menggambarkan apa yang dikehendakinya. Terlebih bila seseorang bertujuan mempengaruhi orang lain, misalnya dalam periklanan.

Iklan merupakan salah satu bentuk pesan. Dalam dunia usaha kebutuhan iklan bagi pengusaha merupakan hal yang penting. Hal ini disebabkan oleh persaingan produk yang semakin ketat. Untuk itulah pembuat iklan dituntut untuk mengemas iklan dengan menarik mungkin.Salah satunya adalah dengan diksi (pemilihan kata-kata) yang tepat dan memberi efek tertentu, sehingga iklan tidak terasa monoton dan membosankan. Iklan dalam sampel terpilih ini menarik untuk dijadikan bahan penelitian karena adanya pemakaian bahasa asing dan daerah dalam iklan tersebut.

Pada penelitian yang dilakukan oleh Ismatul dkk (2015) yang berjudul "Fenomena Penggunaan Bahasa Asing dalam Penamaan Bisnis Kuliner di Kawasan Soekarno Hatta Kota Malang". Disimpulkan bahwa penggunaan bahasa asing cenderung meningkat dalam penamaan bisnis kuliner (hlm.1).

Penelitian ini berfokus pada bahasa atau pilihan bahasa yang digunakan dalam papan usaha dan iklan yang ada di Banjarbaru dan Martapura, (hlm.1)

Permasalahan penelitian ini sebagai berikut.

1. Bagaimana penggunaan bahasa asing dan daerah pada papan nama usaha dan iklan di Banjarbaru-Martapura?

2. Bagaimana penerapan konsep AIDA pada papan nama usaha dan iklan di Banjarbaru-Martapura?

berikut.

Tujuan penelitian ini adalah sebagai

1. Mendeskripsikan pilihan penggunaan bahasa bahasa Inggris dan Banjar pada papan nama usaha dan iklan di Banjarbaru-Martapura;

2. Menjelaskan sebab pemilihan kata dalam papan nama dan iklan menggunakan teori AIDA?

Penelitian ini diharapkan mampu memberikan manfaat untuk pengembangan teori kebahasaan dan menam-bah informasi khazanah penelitian ka-jian sosiolinguistik sebagai disiplin ilmu linguistik yang memusatkan perhatiannya pada gejala kebahasaan di masyarakat. Secara praktis, penelitian ini deskripsi tentang penggunaan bahasa selain bahasa Indonesia yaitu bahasa Inggris dan bahasa Banjar pada papan nama usaha dan iklan di kawasan sekitar Banjarbaru-Martapura beserta penyebabnya. Temuan ini diharapkan memberi 
Penggunaan Bahasa Asing dan Daerah pada Papan Nama Usaha dan Iklan

(Studi Kasus di Banjarbaru- Martapura)

(Nurhidayati Kurniasih)

kontribusi data dasar bagi penelitian lanjutan yang sejenis serta dapat menambah pengetahuan bagi pembaca, peneliti dan para pemerhati masalah kebahasaan.

\section{LANDASAN TEORI}

\section{Bahasa Indonesia}

Bahasa Indonesia sudah memiliki aturan khusus terkait dengan pembentukan kosakata. Setiap kosakata harus berasal dan bersumber dari bahasa Indonesia, jika tidak ditemukan maka harus dilakukan pencarian dari bahasa daerah, dan jika tidak pula didapatkan maka diperbolehkan penggunaan bahasa asing.Penggunaan bahasa asing itu pun harus diterjemahkan terlebih dahulu ke dalam bahasa Indonesia.

Sugiono (2007) menyatakan bahwa penyerapan bahasa asing dengan sangat sembrono terbukti telah memusnahkan kosakata dalam Bahasa Indonesia. Setiap hari mungkin selalu ada kosakata bahasa Indonesia yang hilang akibat kelatahankelatahan yang dipelihara oleh masyarakat dan sistem yang dikelola oleh media massa dan lembaga pendidikan.

Pengindonesiaan kata dan ungkapan asing telah diatur penggu-naannya, sebagai berikut.

1. Bahasa yang digunakan di tempat umum, seperti pada papan nama, papan petunjuk, kain rentang, dan papan iklan adalah bahasa Indonesia yang baik dan benar.

2. Nama badan usaha, kawasan, gedung yang memerlukan pengesahan dari instansi pemerintah menggunakan bahasa Indonesia.

3. Nama asing badan usaha yang merupakan cabang badan usaha luar negeri dan nama asing merek dagang

terdaftar dan mempunyai hak paten tetap dapat.

4. Pada papan nama, papan petunjuk, kain rentang, dan papan iklan digu-nakan tulisan/huruf Latin.

5. Pada papan nama, papan petunjuk, kain rentang, dan papan iklan jika dianggap perlu, dapat dipakai bahasa asing yang harus dituliskan di bagian bawah bahasa Indonesia dengan huruf Latin yang lebih kecil.

6. Penggunaan tulisan/huruf di luar tulisan/huruf Latin, jika dianggap perlu, dapat dibenarkan sepanjang untuk nama/lambang produk yang telah mendapat izin sesuai dengan peraturan perundang-undangan yang berlaku.

7. Organisasi internasional yang bernaung di bawah Perserikatan BangsaBangsa dan perwakilan diplomatik Negara asing dapat tetap menggu-nakan tulisan/huruf dan/atau bahasa asing yang ditulis di bawah nama dalam bahasa Indonesianya. (hlm.4-5).

\section{Pilihan kata}

Dalam Kamus Besar Bahasa Indonesia (1995 dijelaskan, Diksi adalah pilihan kata yang tepat dan selaras (contoh penggunaanya) untuk mengungkapkan gagasan sehingga memperoleh efek tertentu (seperti yang diharapkan). (hlm. 233) Penggunaan pilihan kata dalam menjadi hal yang sangat diperhatikan agar orang menjadi penasaran dengan produk yang dijual dan akhirnya tertarik untuk membeli atau menjadi mudah diingat sehingga produk tersebut yang terlintas pertama kali. Namun ada hal yang perlu diperhatikan dalam pemilihan kata. Kriteria pemilihan kata menurut Mustakin (2015) adalah (1) ketepatan (2) kecermatan (3) keserasian. (hlm. 49) 
Kriteria dalam pemilihan kata tersebut seyogyanya tetap diperhatikan meskipun dalam iklan.

\section{Iklan}

KBBI (2003) mengartikan bahwa iklan diartikan sebagai berita pesan yang disampaikan untuk membujuk khalayak/orang ramai tentang benda atau jasa yang ditawarkan (hlm 421). Dengan demikian, iklan merupakan suatu proses komunikasi yang bertujuan untuk membujuk atau menggiring orang untuk mengambil tindakan yang menguntungkan bagi pihak pembuat iklan dan untuk menarik perhatian dan mendorong atau membujuk pembaca iklan agar memiliki atau memenuhi permintaan pemasang iklan.

Sementara itu bahasa iklan itu sendiri merupakan bahasa yang digunakan untuk membuat iklan. Bahasa yang dianggap bisa menarik orang untuk membeli atau memakai jasa atau barang yang ditawarkan.Untuk menyampaikan gagasan pikiran dalam suatu bahasa seorang penulis iklan harus mengetahui aturan-aturan bahasa tersebut, seperti tata bahasa, kaidah-kaidahnya, dan sebagainya.

Dalam iklan, khususnya bidang pemasaran dikenal kaidah AIDA. AIDA ialah kependekkan dari Attention, Interest, Desire, Action. Ini merupakan model yang cukup sederhana dan dapat digunakan sebagai pedoman. Model AIDA (Attention, Interest, Desire, Action) adalah salah satu model hirarki respon yang cukup popular bagi pemasar sebagai pedoman dalam melaksanakan kegiatan pemasaran. Menurut model ini, alat promosi harus menarik perhatian, mendapatkan dan mendorong minat, membangkitkan keinginan, dan menghasilkan tindakan. Dalam membangun program komunikasi yang efektif, aspek terpenting adalah memahami proses terjadinya respon dari konsumen, misalnya dalam hal konsumen melakukan pembelian suatu produk, maka diperlukan pemahaman mengenai usaha promosi yang dapat mempengaruhi respon konsumen tersebut (danilsyah.blogspot.com).

Teori AIDA (Djatnika, 2007) yang mendalilkan bahwa pengambilan keputusan pembelian adalah suatu proses psikologis yang dilalui oleh konsumen atau pembeli, prosesnya:

1.Tahap memberikan perhatian (Attention) terhadap barang atau jasa. Dengan memberikan perhatian khusus kepada segmen target pasar menjadi perhatian utama bagaimana (calon) konsumen menjadi tertarik dengan apa yang kita tawarkan dan sesuai dengan target pasar yang kita inginkan. Misalnya: "Sayembara Khusus untuk Pelajar!"; ini contoh attention dengan segmen pasar adalah pelajar/siswa dalam sebuah iklan lomba kebahasaan. Coba bayangkan dengan kalimat standar: "Bulan ini bekerjasama dengan Dinas Pendidikan mempersembahkan seminarxx". Kalimat tersebut belum menjelaskan kepada siapa kegiatan (penawaran) ditujukan.

2.Tahap ketertarikan (Interest) untuk mengetahui lebih jauh tentang keistimewaan produk atau jasa tersebut. Memberikan ketertarikan pembaca/prospek untuk lebih membaca lagi iklan/pemasaran tools yang kita tawarkan dengan benefit, keuntungan yang akan didapatkan. Misalnya: "Rasakan Kesegaran Kembali Badan Anda dalam waktu 1 Jam!". Bandingkan jika hanya kalimat, "Ragam Pijat yang bisa Anda Rasakan. 
Penggunaan Bahasa Asing dan Daerah pada Papan Nama Usaha dan Iklan

(Studi Kasus di Banjarbaru- Martapura)

(Nurhidayati Kurniasih)

3.Tahap berhasrat/berminat (Desire) karena barang atau jasa yang ditawarkan sesuai dengan kebutuhan-kebutuhannya. Memberikan rasa/hasrat keinginan dari pembaca untuk mengikuti apa yang kita tawarkan. Biasanya memberikan testimoni para pelanggan yang ada. Lalu memberikan lebih detail apa yang ditawarkan dan apa yang akan didapatkan jika mereka membeli produk/jasa dari kita. Lebih memberikan sebuah emotional benefit kepada mereka sehingga ada keinginan untuk membeli.

4.Tahap terakhir, jika hasrat dan minatnya begitu kuat baik karena dorongan dari dalam atau rangsangan persuasif dari luar maka konsumen atau pembeli tersebut akan mengambil keputusan membeli (Action to buy) barang atau jasa yang di tawarkan. Membuat prospek untuk segera Action, dengan menghubungi kita segera untuk membeli atau mendaftar. Tahapan ini antara lain biasanya berbatas waktu, jumlah, atau hadiah-hadiah/bonus/benefit tambahan agar lebih mendorong konsumen untuk menentukan pilihan. Misalnya: “Dengan menghubungi sekarang juga, Anda akan mendapat Harga Khusus yang lebih Menguntungkan.

Rapp \& Collins (1995) berpendapat bahwa bahasa dalam iklan memang dituntut mampu menggugah, menarik, mengidentifikasi, menggalang kebersamaan, dan mengkomunikasikan pesan dengan koperatif kepada khalayak (hlm.152).

\section{METODE PENELITIAN}

Data penelitian ini diambil sampel purposif berupa papan nama usaha dagang dan iklan yang dipilih untuk keperluan sampel penelitian. Sumber data penelitian ini diambil di Banjarbaru dan

Martapura pada tanggal 1--30 April 2016. Pertimbangan pengambilan data dari sumber data ini yaitu, (1) papan nama usaha menggunakan bahasa Inggris dan atau bahasa Banjar, (2) Papan nama yang diambil ialah asli ada di media luar ruang. Metode pengumpulan data dilakukan melalui pendekatan kualitatif. Pendekatan yang digunakan metode deskriptif, yakni yang mendeskripsikan kesalahan yang ada disampel yang diambil.

\section{ANALISIS DAN PEMBAHASAN}

Membahas penggunaan bahasa Indonesia yang terpinggirkan dalam iklan bukanlah suatu yang baru oleh karena itu peneliti ingin meneliti lebih lanjut terkait dengan penggunaan bahasa asing dan daerah pada papan nama dagang dan iklan yang terdapat di sekitar Banjarbaru dan Martapura.

Sampel diambil berdasarkan penggunaan bahasa asing dan daerah yang digunakan di dalam papan nama dagang dan iklan tersebut. Selanjutnya dianalisis dan disarankan pembetulannya. Berdasarkan konsep AIDA dalam beriklan, sampel dianalisis pilihan katanya sehingga terlihat bagaimana pemilihan kata tersebut mencerminkan konsep AIDA.

\subsection{Deskripsi Penggunaan Bahasa Asing dan Bahasa Daerah di Papan Nama Usaha dan Dagang}

Penggunaan bahasa asing atau bahasa daerah bukan hal yang baru dalam dunia periklanan. Dan papan nama usaha tidak jarang memanfaatkan pilihan kata yang digunakan dalam iklan.

Berikut ini kasus- kasus penggunaan kata berbahasa asing dan bahasa daerah 
yang berhasil ditemukan di wilayah tersebut.

\subsubsection{Kasus Terminal Coklat}

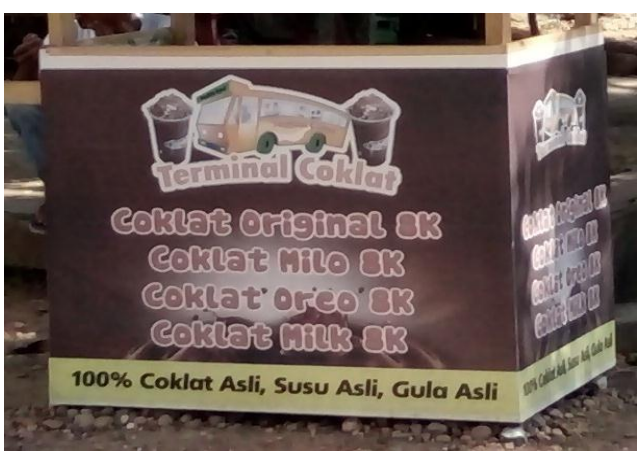

yang tidak terdapat di peraturan penulisan harga dalam ejaan bahasa Indonesia. Bila kita cermati, kesalahan tersebut diatas disebabkan karena mengikuti gaya penulisan satuan kilo yang berarti ribu pada tata bahasa Inggris.

\subsubsection{Kasus Noah Laundry}

\begin{tabular}{|l|l|}
\hline Tertulis & $\begin{array}{l}\text { NOAH LAUNDRY } \\
\text { 1 PELANGGAN, 1 MESIN } \\
\text { CUCI }\end{array}$ \\
\hline $\begin{array}{l}\text { Imbauan } \\
\text { Penulisan }\end{array}$ & $\begin{array}{l}\text { NOAH LAUNDRY atau } \\
\text { LAUNDRI NOAH } \\
\end{array}$ \\
& 1 MESIN CUCI UNTUK 1 \\
& PELANGGAN \\
\hline
\end{tabular}

Penulisan struktur frasa dalam nama merek datang di atas masih menggunakan huku M-D. Semestinya di ubah ke struktur D-M dan menggunakan istilah laundry dalam bahasa Indonesia, yaitu penatu. Pemakaian kata laundry memang telah memasyarakat tetapi ini merupakan kesalahan karena kosakata laundry telah ada padanannya dalam bahasa Indonesia. Pemakaian kosakata laundry ini menunjukan penyerapan budaya layanan cuci pakaian seperti yang ada di luar negeri sehingga kemudian masyarakat menggunakan istilah tersebut.

Pemakaian tanda hubung koma (,) dalam frasa di atas juga kurang tepat. Lebih baik jika digunakan kata hubung untuk sehingga frasanya diubah menjadi 1 mesin cuci untuk 1 pelanggan sehingga memperjelas pelayanan penatu yang mempergunakan satu mesin cuci hanya untuk satu pelanggan dalam pencuciannya. Meskipun kurang tepat, tetapi pengiklan ingin secara jelas menjelaskan detail layanan usahanya yaitu satu mesin cuci untuk mencuci baju satu pelanggan saja (tidak bercampur antarpelanggan) 
Penggunaan Bahasa Asing dan Daerah pada Papan Nama Usaha dan Iklan

(Studi Kasus di Banjarbaru- Martapura)

(Nurhidayati Kurniasih)

\subsubsection{Kasus Falen Ponsel}

Selain kasus Noah Laundry pemilihan bahasa Inggris juga ditemukan pada nama usaha ponsel Falen Ponsel. Kasus seperti Falen Ponsel merupakan salah satu dari sekian banyak papan nama ponsel yang menggunakan nama dengan bahasa Inggris.

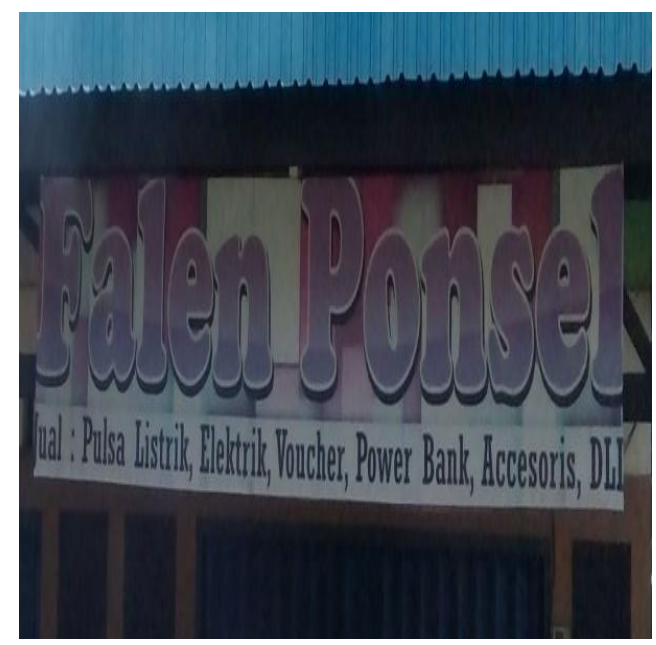

\begin{tabular}{|l|l|}
\hline Tertulis & $\begin{array}{l}\text { Falen Ponsel } \\
\text { Jual: Pulsa Listrik, Elektrik, } \\
\text { Voucher, Power Bank, } \\
\text { Accessories, DLL }\end{array}$ \\
\hline $\begin{array}{l}\text { Imbauan } \\
\text { Penulisan }\end{array}$ & $\begin{array}{l}\text { Ponsel Falen } \\
\text { Jual: Pulsa Listrik, } \\
\end{array}$ \\
& $\begin{array}{l}\text { Elektrik, Vocer, Bank } \\
\text { Daya, Aksesoris, dll }\end{array}$ \\
\hline
\end{tabular}

Kesalahan struktur ada di penulisan Falen Ponsel. Struktur frasa dalam bahasa Indonesia diterangkan-menerangkan. Jadi, seharusnya Falen Ponsel menjadi Ponsel Falen.

Selanjutnya, penulisan kata asing seharusnya diubah mengunakan huruf miring atau dicari padanan katanya dalam bahasa Indonesia. Kata Voucher telah diindonesiakan menjadi kupon atau vocer, Power Bank diindonesiakan menja-

\begin{tabular}{|l|l|}
\hline Tertulis & HJ. ENONG \\
& CARWASH \\
& CUCI \\
& KENDARAAN \\
& DAN \\
& MOBIL \\
& SILAKAN MASUK \\
\hline Imbauan & CARWASH HJ. \\
Penulisan & ENONGatau PENCUCIAN \\
& KENDARAAN HJ. \\
& ENONG \\
& CUCI \\
& SEPEDA MOTOR \\
& DAN \\
\hline
\end{tabular}
aksesoris, dan penulisan DLL yang benar adalah dll.

Kedua jenis kesalahan di atas terkait dengan penggunaan tatabahasa asing, yaitu bahasa Inggris dan pemakaian kosakata bahasa Inggris juga yang sebenarnya telah ada padanannya dalam bahasa Indonesia. Ini membuktikan bahwa papan nama usaha itu ingin terlihat kekinian dan moderen dengan menggunakan tata bahasa asing dan pemakaian beberapa kosakata asing juga.

\subsubsection{Kasus Hj. Enong Car Wash}

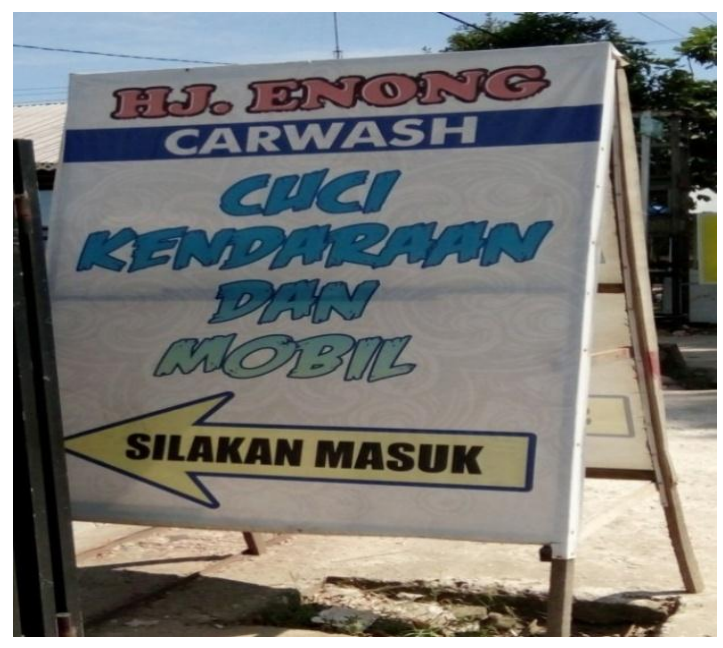




\begin{tabular}{|l|l|}
\hline & MOBIL \\
& SILAKAN MASUK \\
\hline
\end{tabular}

Pada data keempat ini terdapat ambigu dalam pemahaman makna carwash. Apabila diartikan sebenarnya, pengertian carwash ialah cuci mobil saja. Tapi dalam daftar layanan ditulis kata cuci kendaraan dan mobil. Jadi, tempat pencucian itu tidak semata mengerjakan pencucian mobil saja tapi juga kendaraan.

Penggunaan istilah carwash seharusnya diganti dengan kata cuci KENDARAAN atau jika tetap menggunakan frasa tersebut maka penulisannya semestinya memakai huruf miring karena frasa tersebut bukan dalam bahasa Indonesia.

Selanjutnya, penggunaan kata kendaraan dalam CUCI KENDARAAN DAN CUCI MOBIL semestinya menggunakan kata cuci sepeda motor karena kendaraan ialah penyebutan sepeda motor dalam bahasa Banjar. Namun, kata kendaraan menjadi pilihan, sepertinya hal ini dilakukan untuk memperjelas detail pelayanan yang dilakukan. Penggunaan bahasa daerah kendaraan untuk penyebutan sepeda motor merupakan upaya memahamkan konsumen terhadap produk itu dengan menggunakan bahasa daerah.

\subsubsection{Kasus Master IDI \& Friends}

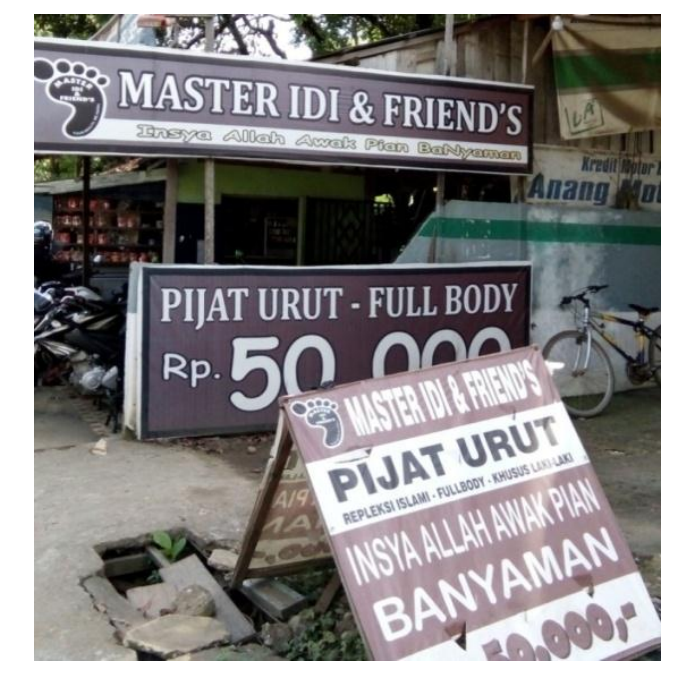

\begin{tabular}{|c|c|}
\hline Tertulis & $\begin{array}{l}\text { MASTER IDI AND FRIEND'S } \\
\text { Insya Alloh Awak Pian } \\
\text { Banyaman } \\
\text { PIJAT URUT - FULL BODY } \\
\text { RP 50.000 } \\
\text { MASTER IDI AND FRIEND'S } \\
\text { PIJAT URUT } \\
\text { REFLEKSI ISLAMI-FULL } \\
\text { BODY-KHUSUS LAKI-LAKI } \\
\text { Insya Alloh Awak Pian } \\
\text { Banyaman } \\
\text { RP 50.000 }\end{array}$ \\
\hline $\begin{array}{l}\text { Imbauan } \\
\text { Penulisan }\end{array}$ & $\begin{array}{l}\text { MASTER IDI DAN REKAN } \\
\text { Insya Allah Awak Pian } \\
\text { Banyaman } \\
\text { PIJAT URUT - SELURUH } \\
\text { BADAN } \\
\text { RP 50.000 } \\
\text { MASTER IDI DAN REKAN } \\
\text { PIJAT URUT } \\
\text { REFLEKSI ISLAMI-SELURUH } \\
\text { BADAN-KHUSUS LAKI-LAKI } \\
\text { Insya Allah Awak Pian } \\
\text { Banyaman atau Insya Allah } \\
\text { badan Anda Membaik }\end{array}$ \\
\hline
\end{tabular}

Merek dagang MASTER IDI AND FRIEND'S justru digunakan karena dinilai punya nilai jual yang lebih daripada menggunakan merek dagang berbahasa Indonesia Bapak Idi dan rekan. Hal yang 
Penggunaan Bahasa Asing dan Daerah pada Papan Nama Usaha dan Iklan

(Studi Kasus di Banjarbaru- Martapura)

(Nurhidayati Kurniasih)

sama terjadi dalam penggunaan frasa dalam bahasa Inggris, yaitu full body yang semestinya diubah ke dalam bahasa Indonesia menjadi seluruh badan.

Meskipun kemudian papan merek dagang ini memilih menggunakan bahasa Banjar untuk lebih mendekati perasaan pembaca (konsumen) yang notabene adalah orang Banjar. Pemilihan kosakata pian dalam Insyaallah Awak Pian Banyaman yang berkonotasi positif meninggikan lawan bicara (konsumen). Pilihan kata pian dipakai untuk menunjukan sikap penghormatan kepada konsumen. Semestinyalnsyaallah Awak Pian Banyaman yang semestinya diganti dengan menggunakan penulisan berhuruf miring Insyaallah Awak Pian Banyaman atau Insyaallah badan Anda Membaik.

\subsection{Penerapan Konsep AIDA dalam Papan Nama Usaha dan Iklan melalui Pilihan Kata}

Konsep AIDA yang merupakan singkatan dari attention, interenst, desire, dan action to buy merupakan konsep yang wajib diperhatikan bagi pengusaha atau pebisnis dalam memperkenalkan produknya kepada khalayak umum yang pada akhirnya akan memutuskan menjadi konsumen atau tidak.

Penerapan konsep AIDA diwujudkan dalam pemilihan kata.

\subsubsection{Konsep Attention 'perhatian'}

Reaksi memberi perhatian dapat disebabkan oleh dari dalam diri konsumen maupun dari luar konsumen. Reaksi ini dipancing oleh objek yang memiliki kelebihan, bentuknya maupun pilihan kata yang digunakan. Pilihan kata yang tepat dan unik akan mudah memancing perhatian calon pembeli atau pengguna jasa.

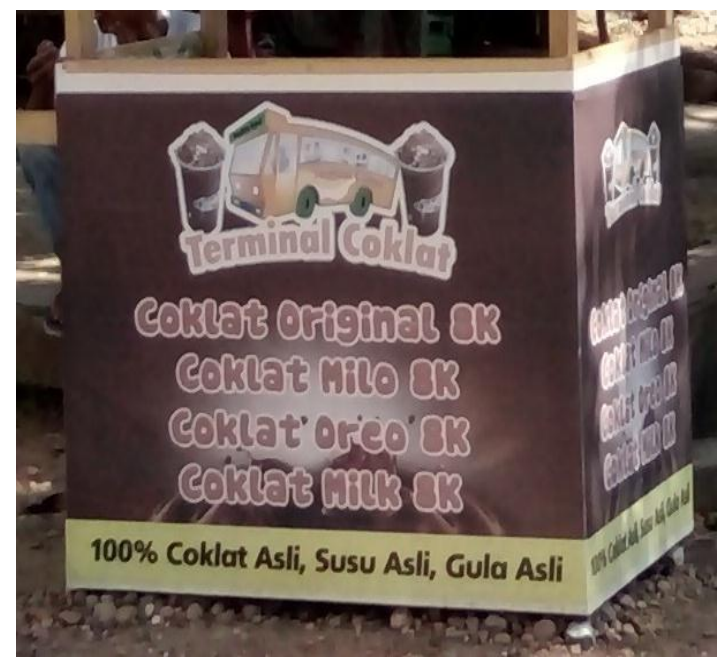

Pilihan kata "terminal coklat" merupakan pilihan kata yang unik, karena memiliki daya tarik untuk menarik perhatian (attention) pembeli atau konsumen terha-dap barang atau jasa yang ditawarkan. Ungkapan "terminal coklat" memberi efek menarik perhatian, konsumen penggemar coklat tentu akan mengingat letak lokasi yang menawarkan sajian utama bermacammacam coklat tersebut.

Demikian juga dengan pengunaan konsonan $\mathrm{k}$ yang mengacu pada $\mathrm{rb}$. Meskipun ini tidak terdapat dalam penulisan satuan harga di Bahasa Indonesia tetapi ini dipakai mengacu pada pola tulisan dalam media social yaitu k sama dengan ribu. Sebagaimana penulisan 320k followers dalam sebuah instagram sebagai contoh. Jadi 320k followers itu berarti bahwa instagram itu telah diikuti oleh 320 ribu pengikut. Penyamaan penulisan harga minuman dengan gaya penulisan bahasa Inggris ini tidak sesuai dengan kaidah penulisan penyingkatan satuan dalam bahasa Indonesia. Satuan harga dalam bahasa Indonesia ditulis lengkap, misalnya puluh, ratus, ribu dan seterusnya. 


\subsubsection{Konsep Interest 'tertarik'}

Pemilihan kata yang tepat pada papan usaha dan iklan akan menimbulkan daya tarik pembaca / prospek untuk mengetahui lebih banyak lagi iklan/pemasaran tools yang kita tawarkan dengan benefit, keuntungan yang akan didapatkan.

Pemaparan poin layanan yang mengedepankan nilai lebih dari usaha/produk yang diiklankan. Penggunaan bahasa yang bombastis atau diluar kebiasaan menjadi pilihan dengan maksud menjadikan konsumen tertarik terhadap usaha/produk yang diiklankan. Pemilihan kata yang memperlihatkan hal tersebut terlihat pada contoh berikut.

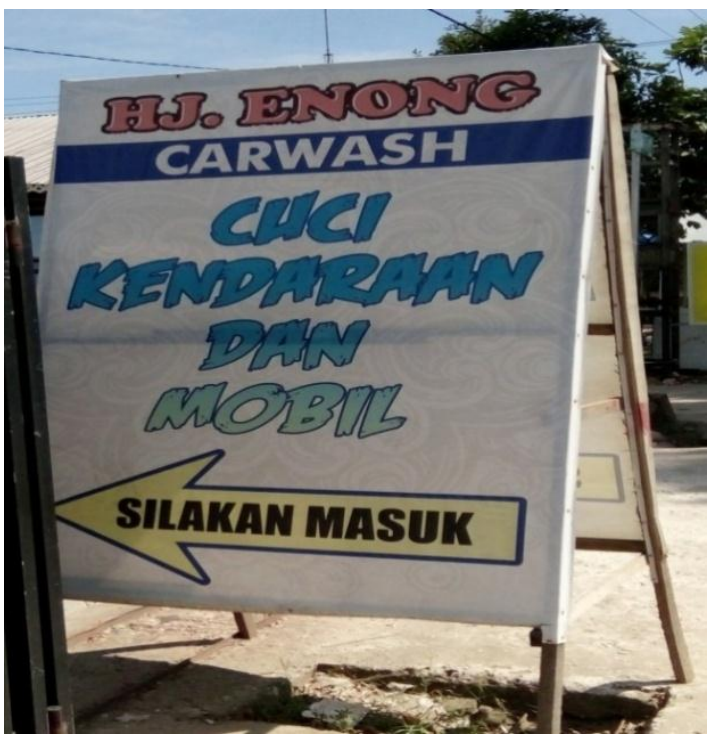

Pada gambar tersebut memperlihatkan penggunaan bahasa asing sebagai nama jasa layanan yang ditawarkan. Kata carwash 'pencucian mobil' lebih memiliki daya tarik yang akan mendorong konsumen untuk datang dan menggunakan layanan tersebut. Efek tersebut tidak akan muncul jika pilihan kata yang digunakan adalah pencucian mobil.

\subsubsection{Konsep Desire 'berhasrat'}

Memberikan rasa/ hasrat keinginan dari pembaca untuk mengikuti apa yang kita tawarkan biasanya memberikan testimoni para pelanggan yang ada. Kemudian, iklan memberikan lebih detail apa yang ditawarkan dan apa yang akan didapatkan jika mereka membeli produk/jasa dari kita. Lebih memberikan sebuah emotional benefit (keuntungan secara emosional) kepada mereka sehingga ada keinginan untuk membeli.

Dalam penelitian ini ditemukan bahwa frasa atau istilah daerah digunakan untuk lebih masuk ke dalam perasaan konsumen.

MASTER IDI AND FRIEND'S

Insya Alloh Awak Pian Banyaman

PIJAT URUT - FULL BODY

RP 50.000

MASTER IDI AND FRIEND'S

PIJAT URUT

REFLEKSI ISLAMI-FULL BODY-KHUSUS

LAKI-LAKI

Insya Alloh Awak Pian Banyaman

RP 50.000

MASTER IDI DAN REKAN

Insya Allah Awak Pian Banyaman

PIJAT URUT - SELURUH BADAN

RP 50.000

MASTER IDI DAN REKAN

PIJAT URUT

REFLEKSI ISLAMI-SELURUH BADAN-

KHUSUS LAKI-LAKI

Insya Allah Awak Pian Banyaman atau Insya

Allah badan Anda Membaik

Pilihan kata baik yang berujud kata, frase maupun kalimat dalam bahasa daerah memberi kesan unik pada papan nama usaha layanan jasa tersebut. Keunikan terletak pada pilihan kata bahasa Inggris MASTER IDI AND FRIEND'S tentu merupakan hal yang tak 
Penggunaan Bahasa Asing dan Daerah pada Papan Nama Usaha dan Iklan

(Studi Kasus di Banjarbaru- Martapura)

(Nurhidayati Kurniasih)

lazim, karena bisa dipastikan bahwa si pemilik nama usaha tersebut bukan penduduk asing. Kesan ini diperkuat dengan penggunaan kalimat berbahasa Banjar Insya Allah Awak Pian Banyaman. menghasilkan efek familiar terhadap masyarakat setempat.

\subsubsection{Konsep Action to buy 'membeli'}

Jika hasrat dan minatnya begitu kuat baik karena dorongan dari dalam atau rangsangan persuasif dari luar maka konsumen atau pembeli tersebut akan mengambil keputusan membeli (Action to buy) barang atau jasa yang di tawarkan.

Dalam konsep ini, penelitian ini tidak membahas karena keterbatasan data yang ada dalam papan nama.

\section{PENUTUP}

\subsection{Simpulan}

Simpulan dari hasil analisis data dan pembahasan diuraikan sebagai berikut ini.

5.1.1 Secara singkat deskripsi penggunaan bahasa asing dan daerah terlihat dari pilihan kata dan struktur kalimat yang digunakan pada data.

5.1.2 Penerapan konsep AIDA menunjukkan bahwa:

1. Penggunaan symbol $(K)$ yang menjadi ikon kekinian menjadikan pengiklan menggunakan simbol tersebut untuk menarik perhatian (attention) konsumen terhadap barang atau jasa.

2. Penggunaan pilihan kata yang bombastis atau diluar kebiasaan dengan menggunakan tatabahasa dan pilihan kata yang tak lazim (asing) menjadi pilihan dengan maksud menjadikan konsumen

tertarik (desire) terhadap usaha/produk yang diiklankan.

3. Penggunaan bahasa daerah merupakan upaya menarik perhatian konsumen terhadap variasi pelayanan. Selain itu bahasa daerah dipilih untuk lebih mendekatkan (interest) konsumen dengan detail atau pilihan layanan. Penggunaan frasa atau istilah daerah dimaksudkan untuk lebih masuk ke perasaan konsumen. Sebaliknya, penggunaan bahasa Inggris untuk memberikan kesan modern pada pembaca iklan karena tahu kosakata yang dipakai dalam dunia maya.

\subsection{Saran}

Berdasarkan simpulan di atas, penulis menyampaikan masih ada kesalahan berbahasa dalam periklanan. Hal ini entah disengaja atau karena ketidaktahuannya dalam pengunaan bahasa Indonesia di media luar ruang. Semoga temuan ini menjadi peringatan bahwa bahasa dalam iklan meskipun mempunyai pedoman sesuai dengan kaidah AIDA semestinya tetap mengikuti kaidah penulisan bahasa Indonesia.

\section{DAFTAR PUSTAKA}

Djatnika, Tjetjep, (2007). Komunikasi pemasaran. Bandung. PT Remaja Rosdakarya.

Departemen Pendidikan Nasional. (2003). KBBI. Jakarta: PT Gramedia Pustaka Utama.

Khasanah, Ismatul dkk.(2015). Fenomena penggunaan bahasa asing dalam penamaan bisnis kuliner di kawasan Soekarno Hatta kota Malang. Banten: IWI ProvinsiBanten. http://juliwi. com/2015/02 
Undas, Vol 14, No 1, Juni 2018: 93-103

(diunduh Oktober 12, 2017 10.30)

Mustakim. (2015). Bentuk dan pilihan kata. Jakarta: Departemen Pendidikan Nasional.

Rapp, Stan \& Tom Collins. (1995). Terobosan baru dalam strategi promosi, periklanan, dan promosi, Maxi Marketing. (terj. Hifni Alifahmi). Jakarta: Erlangga.

Sugono dkk. (2007). Pengindonesiaan kata dan ungkapan asing. Jakarta: Departemen Pendidikan Nasional. http://danilsyah.blogspot.com/2011/07/pe ngertian-aida-dalam-kewirausahaan.html (diunduh September 8,2017 14:15) 
Penggunaan Bahasa Asing dan Daerah pada Papan Nama Usaha dan Iklan (Studi Kasus di Banjarbaru- Martapura)

(Nurhidayati Kurniasih) 